\title{
Research on Geometrical Patterns on Yao Nationality Clothing
}

\author{
Ting Rong ${ }^{1}$ \\ ${ }^{1}$ Fashion \& Art Design Institue, Donghua University, Shanghai, China \\ Correspondence: Ting Rong, Fashion \& Art Design Institue, Donghua University, Shanghai, China. \\ rongting198396@163.com
}

Received: September 15, 2015 Accepted: October 16, 2015 Online Published: November 20, 2015

doi:10.5539/ass.v11n27p263

URL: http://dx.doi.org/10.5539/ass.v11n27p263

\begin{abstract}
The Yao nationality has a long history, splendid Civilizations, numerous sub-lines and clothing in riotous profusion. Among which, the greatest characteristic is various geometrical patterns on Clothing. This essay divides geometrical patterns on Yao nationality clothing into patterns with pure ides forms simply formed by point, line and surface; patterns formed by highly abstract generalization through imitation and symbolization to natural objects and man-made objects; and patterns represent historic Civilization and religious belief of Yao nationality. On this basis, this essay analyzes constitution forms of geometrical patterns on Yao nationality clothing, summaries the ornament position on clothing and technology embodiment of these patterns. In the end, this essay tries to discuss their forming reasons and historic embodiment.
\end{abstract}

Keywords: Yao nationality clothing, geometrical pattern, constitution form, forming reason

\section{Introduction}

Geometrical pattern is a kind of decorative pattern which is used earliest in Chinese silk fabric which very abstracted and acknowledged widely. As decorative pattern, geometrical pattern was applied maturely in colored pottery vessels as early as 5 thousand years ago; it was used as decoration of clothing as early as slave society period.

The Yao nationality has a long history and its clothing is in riotous profusion. The design patterns appeared as one kind of decoration method. The design patterns of Yao nationality are in thousands of postures which are colorful and complex; they involve almost all natural flowers \& plants, birds \& animals and clouds \& water, and imaginative dragon, phoenix and Kylin. Among which, geometrical pattern is a kind of design pattern of Yao nationality clothing which is used mostly and owns most ethnic characteristics. It has diverse forms, remarkable characteristics and rich valid sculpts.

This essay discusses the characteristics of geometrical patterns of Yao nationality clothing from the following aspects.

\section{Types and Connotations of Geometrical Patterns on Yao Nationality Clothing}

According to differences in contents, the geometrical patterns of Yao nationality clothing can be divided into 3 types. Details are as follows:

\subsection{Patterns with Pure Ides Forms That Is Simply Formed by Point, Line and Surface}

These are highly abstract geometrical patterns include various diamonds, squares and triangles, etc. that are formed by straight lines and folded straight lines. In specific, these include clouds pattern, thunder pattern, Chinese word "ri" pattern, wave pattern, diamond pattern, zigzag pattern, svastika pattern, cross pattern, hook-linkin pattern, circle pattern, pinniform pattern and sawtooth pattern, etc. Normally, the main pattern of Yao nationality ribbon is geometrical abstract pattern formed by diamond-type lattices and oblique lines, such as integration pattern on ribbon of folk master of Pan Yao. Hook-linking pattern is one very old pattern, clouds and thunder pattern on bronze ware is a kind of hook-linkin pattern. They are called as hook-linking pattern because their lines bend like hook-like, and connected scatteredly.

2.2 Patterns Formed by Highly Abstract Generalization through Imitation and Symbolization to Natural Objects and Man-Made Objects

These patterns are highly abstract results of animals \& plants in nature. Through lengthy historical sediment, 
these patterns have been highly abstracted which can only be reorganized by people in the same nation. There are various highly abstract geometrical patterns on rich dress of girls in Youlingpai Yaozu of Guangdong Liannan Yaozu Zizhixian, such as grass pattern, bridge pattern, niuhong pattern, bird pattern, tree pattern, ox horn pattern, champaign pattern and girl pattern, etc. You can never find out figurative shapes in them, but they represent all things on earth in nature that are special symbol representatives of this nation (Figure 1).

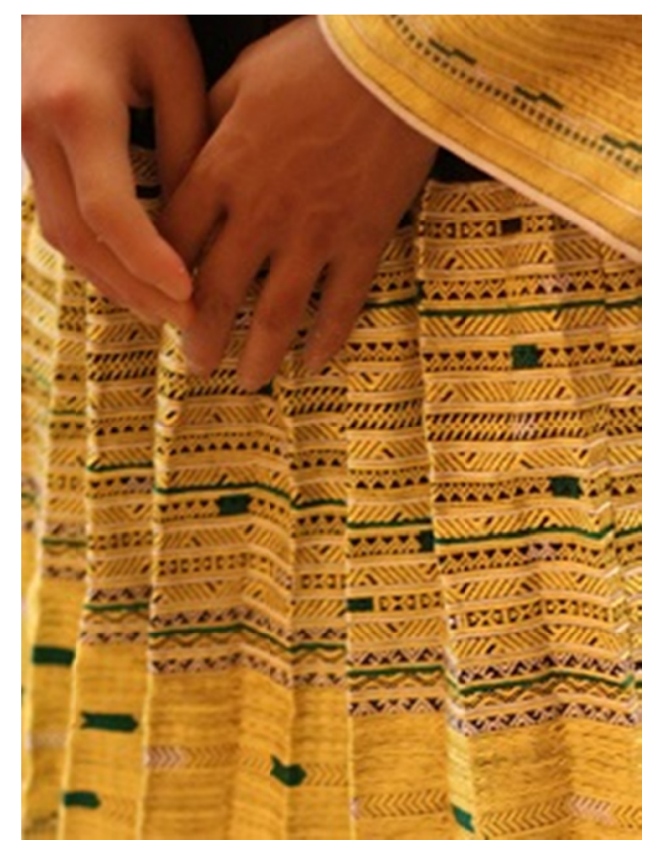

Figure 1. Rich Dress (Dress) of Woman from Liannan Youling, collected in Guangdong Yao Nationality Museum

\subsection{Patterns Represent Historic Civilization and Religious Belief of Yao Nationality}

These patterns have been in Yao Nationality for a long time, which can often be seen on constumes and used as symbolization representatives of religious belief, national heroes and national ancestral owned by Yao Nationality, such as, the King of Pan Pattern is to honor the ancestor king who is the nationality's belief. There is a rarely big, square and colorful pattern respectively in the left and right sides below the coattail of Hong Yao women from Longsheng, Guangxi. People call it "Tiger Paw Print". This print also has its uncommon origin. A legend has it that long time ago, the emperor was in his imperial visit passing by precious jade hill, but suddenly chased by a wild tiger. At this time, he happened to meet a brave Yao girl, who came forward to save the emperor But in the fight with the tiger, the girl's waist was scratched by it. After knowing about this, the emperor promulgated an imperial decree: Yao girls who had tiger scratch marks in the waist should be protected. After knowing the decree, the Yao women's clothes were also embroidered with tiger paw print. On the one hand, they made themselves protected by the court. On the other hand, it is more important to be in memory of the heroic Yao girl.And five vertical red streaks on trousers of men from Baiku Yaozu (Figure 2). It is said that the five vertical red streaks are "blood fingerprint" left by heroical ancestors on trousers broken up to knee in one heroic war, the descendants use red silk thread to embroider the same shape on trousers to cherish the memory of their revolutionary martyrs. 


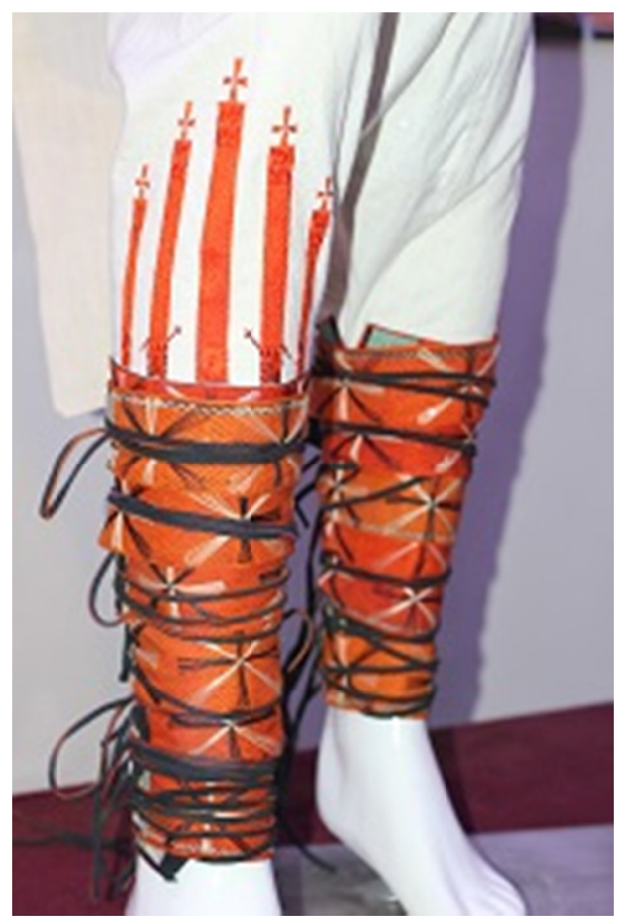

Figure 2. Clothing of Man from Guangxi Nandan County Baiku Yaozu, collected in Guangxi Nationality Museum

\section{Constitution Forms of Geometrical Patterns on Yao Nationality Clothing}

The forms of geometrical patterns on Yao nationality clothing are various, they have remarkable characteristics and rich valid sculpts. The design patterns formed by point, line and surface tie in, and make a distinction between the important and lesser one with ordered density, and rich in rhythm sensation and rhythmical images. Their constitution forms include both single pattern and continual pattern.

Single pattern include suit pattern, corner pattern and margin pattern. Suit pattern is normally formed by orderly organization forms, it adopts format of longitudinal symmetry or bilateral symmetry and divide configuration with construction in neat formation. Its main bone methods are vertical type and radiation type. This kind of pattern has various changes and artful composition, include circle, triangle, square inside circle or circle inside square, etc; they are all in valid composition and beautiful form. Most of flower cluster, angle flower and various inside skeleton patterns are suit pattern. Sometimes, Yao people hand-stitching suitable figures from fixed image which forms well-decorative pattern with figure inside figure that reflects imagination and creativity of Yao people. The bone method in corner pattern mainly is symmetric style. The composition bone method in margin pattern mainly is continual system.

Continual patterns include two sides continual and four sides continual, specific information as follows:

\subsection{Two Sides Continual Pattern}

It is mostly used on clothes ornament, weigela florida and lace. Composition bone methods of main basic unit include: vertical type, decorative patterns are up, form symmetry form; diagonal type, decorative patterns are lean at $45^{\circ}$ angle, towards left or right; broken line type, the bone is formed by wavelike straight lines, the pattern can be arranged on wave lines or inside wave belly; geometry type, formed by geometry texture, fill suitable patterns in geometry shape. Some two sides continual patterns can be used repeatedly and overlapped, with separated width and relative density, accompanied by various colors will present splendid picture.

\subsection{Four Sides Continual Pattern}

It is mostly used to make large-size like entering bed mat, bed blanket, curtain edge and skirting, etc. It has widespread themes and various decorative patterns. Most of these patterns add suitable patterns in shade formed by respective bones, some patterns adopt radial bones developing towards al all directions, and some patterns are in symmetric figures in alignment with strict rule. Four sides continual pattern takes cluster as main constitution form, among which diamond cluster is in the majority. 
The constitution form of geometrical patterns on Yao nationality clothing mainly follows the method of uniformity, balance, continuation and repeat. Thus, the weight component among up and down, left and right, intermediate and opposite angles of the pattern picture should be arranged at proper dimension, which meets mechanical theory, obtains balanced and stable form with combination of equal quantity and different forms, and creates feeling of solemn, steady and peace. Continuation is the connection unify among changes; repeat is regular extension continuation. Nature and natural movement changes are always repeat appearance regularly. Therefore, the constitution form of geometrical patterns on Yao nationality clothing follows the rules of aesthetic and nature that it forms its unique charm.

From the perspective of design structural forms, the design patterns of Yao Nationality clothing can be generally divided into three types: Some makes the geometrical patterns be the main patterns, plants with colorful and varied patterns as a foil, which makes a distinction between the important and lesser one of the patterns; some uses patterns of plants and animals to serve as the main patterns, which has rich and colorful geometric patterns to make up the grain belt and let geometric patterns play a part in foiling and beautifying the main patterns; some are almost full of geometric patterns, using different patterns to be combined interspersedly, making the whole patterns coordinated and giving people a complicated and magnificent feeling. (1)

\section{Ornament Position on Clothing and Technology Embodiment of Geometrical Patterns on Yao Nationality Clothing}

Almost all parts of Yao nationality clothing are decorated by geometrical patterns of Yao nationality, mainly in parts with rich dynamic sense, such as sleeves, trousers legs, shoulders, chest, bosom, back, waist and sweep; clothing accessories like shawls, corsets, belts, headscarf and shoes; even bag and bed sheets; which show us the wide use of geometrical patterns in Yao nationality clothing and livelihoods.

The decorating technologies of Yao nationality clothing are formation basis of pattern characteristics. The decorating technologies of geometrical patterns on Yao nationality clothing include embroidery, hand-stitching work, wax printing, brocade and patch work. Embroidery is used most in decorating technologies of Yao nationality Clothing, the craft process of embroidery are according to lattice and silk on base fabric, embroider an x-type pattern on each lattice, connect many x-type patterns in paralleling to form all kinds of continual patterns. There are close related causal relationships between weaving process of broche and stylize performance of ornamentation patterns. The original handwork fabrics made by interlace in longitude and latitude promote folk brocades from different nationalities regions even worldwide present dot-matrix pattern style under geometry rules and constitution form by folded straight line, due to their technologies limitation.

\section{Forming Reasons and Historic Embodiment of Geometrical Patterns on Yao Nationality Clothing}

Yao nationality is an old nation, its history can trace back to ancient period which can not be cut apart with Sanmiao tribe. They are also called as "Nanman", because they lived in Hanjiang River Badin and south of Hanjiang River Badin. Sanmiao tribe develops its influence sphere continuously that resulted in conflict fighting with Huaxia tribe which was also in expansion stage, and Sanmiao tribe finally failed. Parts of losing Nanman tribe members started southward migration. Hereafter, centre governments of successive dynasties conducted suppress to south ethnic minorities including Yao Nationality, the ancestors of Yao Nationality migrated to south remote mountains area continuously to survive, they could not settle down to develop agriCivilization all the time that they were always in production living conditions of shifting cultivation. Due to obstruct among mountain regions, the distribution mode of Yao nationality is "scattered in large-scale, community in small-scale" that Yao people are difficult to form powerful political system and force. Yao nationality society is always in closed and backward state with deficient material life and blocking Civilization. Technologic limitation resulted from lagging economy and closed living environment made their decoration techniques on clothing are relatively single, which mainly include hand-stitching work and brocade. Both hand-stitching work and brocade are limited by longitude and latitude of cloth to a great extent, that they have certain difficulty in making figurative patterns. Human's awareness of themselves and appreciation in the external things needs to be established after breaking free from the pressure of survival. Only after material life is relatively wealthy and stable can they pay more attention to the spiritual level and art extends and develops towards a higher direction. With no living guarantee, Yao ancestors first focused on how to get rations from the poor land. In this environment, they did not have much energy to draw landscape flowers and birds and their aesthetic ability of art to some extent still remained in that distant ancient era. Abstract geometrical patterns in brocade reflect its origin relations with geometrical patterns in different ancient periods from its longitude and latitude weaving. (2)Brocade of Yao nationality can be reflected corresponding to Chinese Word "Hui" pattern, diamond pattern, thunder pattern and rectangle pattern in Shang and Zhou Dynasties from its organization style. However, the main reason why Miao 
nationality with which they have an original genetic relationship produced those figurative patterns with rich expressiveness and imaginativeness is that Part of the Miao lived in a relatively open environment and lived together with Han nationality. Since the land is relatively broad flat, easy to cultivate and trafficking of goods can obtain economic security, the economy developed greatly and consequently brought the development of culture. Its decorative patterns developed from relatively primitive abstract geometric patterns to figurative patterns with a variety of performance methods. Because of its aesthetic development, the garment decoration technologies need to have technical exchanges with Han. Thereafter, it appeared flat embroidery, lock embroidery, embroidered fight seeds, Duixiu and other embroidery methods. The acquisition and emergence of these methods further enrich the performance practices of design patterns on clothing. But we also find that not all of the Miao depict and embroider figurative patterns. As with Jinxiu Yao, those areas of Miao in closed and remote places where people lived and have little contact with the Han and economic life is relatively backward have its patterns stay in the stage of geometric patterns. Thus, we can see that economic development and how to develop indeed to a large extent determine the pace and direction of development of a nation's civilization and the stage of development of their art and aesthetic appreciation. And, some geometrical patterns of Yao nationality also inherit geometrical patterns arisen in the Neolithic Age. Such as, sun patterns on Yao nationality clothing ; they are similar to eight-angles sun patterns in colored pottery bowls unearthed from Jiangsu Pi County Dadunzi of Dawenkou Civilization and colored pottery jars in Machang type of Majiayao Civilization.

Many geometrical patterns on Yao nationality clothing is abstract and hard to understand, that few people know the significance. The reasons may be as follows: some geometrical patterns are inherited from ancient ages surely; they had their signified contents at that time, because Yao nationality had no words to write down the contents that the contents transformed, distorted, dimmed and disappeared finally during the spreading process. These geometrical patterns turn to be pure decorative patterns finally. Due to they have significant meanings at the beginning, that use of them must obey strict normative that can't be changed at will. Patterns have their own names in Yao language that the names are in inheritance and authenticity during the process of passing form mouth to mouth. But initial names could also disappear due to patterns losing their original meanings, but Yao people will arrange new names for patterns according to meaning of that time to inherit them, thus many patterns are unworthy of the name anymore.

Yao nationality has a large number of branches. All branches scatter among remote places with different adjacent nationalities. Influenced by natural environment and adjacent nationalities, their design patterns on clothing are also different. Generally speaking, people who live in the plains and Pingba region has more contact with Han nationality and other advanced nationalities. The branch with advanced economy and culture tends to have richer, more variegated and abstract design patterns on clothing. However, people who live in the mountains usually have less contact with Han nationality and other nationalities. The branch with relatively slow economic and cultural development often has simpler, quainter and more figurative patterns on clothing. (3)

\section{Conclusion}

The geometrical patterns on Yao nationality Clothing is not only one kind of decoration, but also one kind of public symbol which is used as one kind of communication media to record history and transmit one kind of common cultural value system. From the perspective of development of ornamentation, most images and ornamentations on formative arts in hunting civilization and primary agricultural civilization are abstract geometric patterns, among which two sides continual pattern and four sides continual pattern are majorities. These images and ornamentations take symbol and expression as aim instead of depicting and objects representation. The need from people is much more important than development degree of techniques. Most ornamentation in early colored potteries is representational, later and more abstract. Not because people lost their early representational ability, but they turned this ornamentation into certain mark or symbol which can only be recognized by people of the same clan, that is similar to one kind of pictograph. The geometrical patterns on Yao nationality clothing can be used to record history, or indicate identity, or imply lucky, or drive out evil spirits and protect people. These patterns are related to historical memory of origin and migration of Yao Nationality, long-term migration career produce carry-on ethnicity cultural style, all ethnicity history settled in behaviors of oral legend, complex costume patterns and body decoration. Thus, the geometrical patterns on Yao nationality clothing are results of Yao nationality historical Civilization and social comprehensive construction. Through this, Yao nationality expresses its self-identity to historical memory, and inherit and "reappear" historical memory generation to endless life.

\section{Acknowledgements}

This work was supported by the Ministry of Science and Technology of the People's Republic of China 


\section{(2013BAH58F01).}

\section{References}

Fang, L. (2014). Local Vision of Art Anthropology. Beijing: China Federation of Literary Press.

Guangxi Yaozu Studies Academy of Guangxi Museum of Ethnography. (2013). Yaozu Studies Research (Section 9). Nanning: Guangxi People's Publishing House.

Yu, S. (2012). Yao Nationality Clothing. Beijing: Beijing Science and Technology Press.

Zhejiang Academy of Fine Arts Patterns Textbook Compilation Group. (2014). Basic Design Techniques. Beijing: People's Fine Arts Publishing House.

\section{Notes}

Note 1. Yu Shijie: Yao Nationality Costumes, Beijing, Beijing Science and Technology Press, Edition 1 of June 2012, Page 58.

Note 2. Zuo Hanzhong: Hunan Folk Fine Arts Collection Folk Brocade, Changsha, Hunan Fine Arts Press,, Edition 1 of November, 1994. Page 38.

Note 3. Yu Shijie: Yao Nationality Costumes, Beijing, Beijing Science and Technology Press, Edition 1 of June 2012, Page 58.

\section{Copyrights}

Copyright for this article is retained by the author(s), with first publication rights granted to the journal.

This is an open-access article distributed under the terms and conditions of the Creative Commons Attribution license (http://creativecommons.org/licenses/by/3.0/) 